\title{
An 11-year-old boy with chronic diarrhea and weight loss
}

\author{
Maimuna Sayeed, Nazmul Hassan, Md. Rukunuzzaman and Bishnu Pada Dey
}

\section{Article Info \\ Department of Pediatric Gastroenterol- ogy and Nutrition, Faculty of Pediatrics, Bangabandhu Sheikh Mujib Medical University, Dhaka, Bangladesh (MS, NH MR); Department of Pathology, Faculty of Basic Science and Paraclinical Sci- ence, Bangabandhu Sheikh Mujib Medi- cal University, Dhaka, Bangladesh (BPD) \\ For Correspondence: \\ Maimuna Sayeed \\ dr.maimuna.sayeed@gmail.com \\ Received: \\ Accepted: \\ 25 January 2020 \\ Available Online: 19 February 2020}

ISSN: 2224-7750 (Online)

2074-2908 (Print)

DOI: 10.3329/bsmmuj.v13i1.45230

Keywords: Diarrhea; Solitary rectal ulcer syndrome; Weight loss

Cite this article:

Sayeed M, Hasan N, Rukunuzzaman M, Dey BP. An 11-year-old boy with chronic diarrhea and weight loss. Bangabandhu Sheikh Mujib Med Univ J. 2020; 13: 35 41.

\section{Copyright:}

The copyright of this article is retained by the author(s) [Atribution CC-By 4.0]

\section{Available at:}

www.banglajol.info

A Journal of Bangabandhu Sheikh Mujib Medical University, Dhaka, Bangladesh

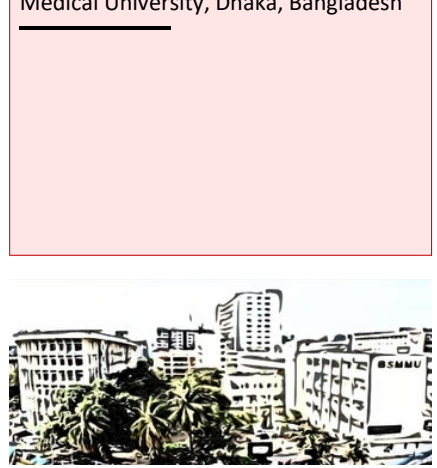

\section{Presentation of Case}

Dr. Maimuna Sayeed: An 11-year-old boy presented with 15 months history of diarrhea with up to 10-20 times small volume stool daily with mucus. It was associated with a feeling of incomplete defecation and excessive straining. The frequency of diarrhea increased to 20-30 times per day over the last 8 months. Subsequently, he developed fecal incontinence, for which he couldn't attend his school. He also had a history of significant weight loss in the last 7 months. According to his mother's statement, his body weight was reduced to $64 \mathrm{~kg}$ from $77 \mathrm{~kg}$ during this illness. In spite of receiving several antibiotics and antidiarrheal medications prescribed by a registered physiccian, his symptoms had not resolved. He had no history of constipation, self-digitation, per rectal bleeding, fever, anal or abdominal pain, oral ulcer, skin lesion, joint pain, TB contact, and no significant family history. There was no evidence of any significant visible rectal prolapse. During his course of illness, he was symptom-free for 4 months irrespective of any treatment.

The findings of the physical examination were unremarkable. He was mildly pale, afebrile, not dehydrated, skin survey was normal, BCG mark was present, lymph nodes not enlarged and vitally stable. His anthropometric measurements were at $97^{\text {th }}$ percentile for weight $(59 \mathrm{~kg})$, at $95^{\text {th }}$ to $97^{\text {th }}$ percentile for height and body mass index for age at $95^{\text {th }}$ to $97^{\text {th }}$ percentile. The abdomen was soft and non-tender with no organomegaly or ascites, bowel sound was present. Perianal findings and digital rectal examinations were unremarkable. Other systemic examinations revealed no abnormality.

Laboratory findings revealed normocytic normochromic anemia (hemoglobin $9.7 \mathrm{~g} / \mathrm{dL}$, mean corpuscular volume $89 \mathrm{fL}$, mean corpuscular hemoglobin $28 \mathrm{pg} /$ cell, mean corpuscular hemoglobin concentration $31 \mathrm{~g} / \mathrm{dL}$, hematocrit $33 \%)$, white blood cell count was normal $(7.0 \mathrm{x}$ $10 \%$ L, neutrophil $52 \%$, lymphocyte $40 \%$, monocyte $6 \%$, eosinophil $2 \%$ ) platelet count normal $\left(250 \times 10^{9} / \mathrm{L}\right)$, normal erythrocyte sedimentation rate $\left(30 \mathrm{~mm}\right.$ in $1^{\text {st }}$ hour $)$ and high-sensitivity C-reactive protein $(0.61 \mathrm{mg} / \mathrm{L})$, serum albumin normal (39 g/L), occult blood test negative and Monteux test negative ( $2 \mathrm{~mm})$.

X-ray chest and abdomen were normal (Figure 1).

Stool examination was done repeatedly for ova, parasite and culture was found negative (Table I).

Prof. Md. Rukunuzzaman: Colonoscopy findings revealed rectal mucosal nodularity and ulceration. (Figure 2). The mucosa and vascular pattern of the rest of the colon appeared to be normal. Multiple biopsies were taken from the lesions.

Dr. Bishnu Pada Dey: Histopathological examination revealed moderate infiltration of chronic inflammatory cells in the lamina propria and surface erosion. The crypts were diamondshaped. The muscularis mucosa was thick and thin bands of smooth muscle fibers were present in between the crypts. No granuloma or malignancy was seen (Figure 3). The diagnosis was compatible with the solitary rectal ulcer.

\section{Provisional Diagnosis}

Solitary rectal ulcer syndrome

\section{Differential Diagnosis}

Dr. Luthfun Nahar: As the patient presented with chronic diarrhea and significant weight loss, the duration is long and also as Bangladesh is a highly endemic zone for the tuberculosis, so after considering these facts and evaluating the other features, it could be a case of intestinal tuberculosis.

\section{Intestinal tuberculosis}

Chronic diarrhea in children is one of the most common clinical presentations of intestinal tuberculosis. Malnutrition, overcrowding, poverty and HIV co-infection aid the spread of tuberculosis.1 Mycobacterium tuberculosis and M. bovis are the principal cause of intestinal tuberculosis. Tuberculous bacilli can infect the gastrointestinal tract by the following route: a) hematogenous spread from primary lung focus; b) ingestion of bacilli from the infected sputum; 


\begin{tabular}{|lcr|}
\hline \multicolumn{3}{|c|}{ Table I } \\
\hline \multicolumn{3}{|c|}{ Laboratory investigations of the patient } \\
\hline Parameter & Findings & References \\
\hline Hemoglobin (g/dL) & 9.7 & $15 \pm 2$ \\
WBC count (×10\%/L) & 7.0 & $7.0 \pm 3$ \\
Differentials & & \\
Neutrophil (\%) & 52 & $40-80$ \\
Lymphocyte (\%) & 40 & $20-40$ \\
Monocyte (\%) & 6 & $2-10$ \\
Eosinophil (\%) & 2 & $1-6$ \\
Platelet count (109/L) & 250 & $0-10$ \\
Erythrocyte sedimentation rate \\
(mm in 1st hour)
\end{tabular}

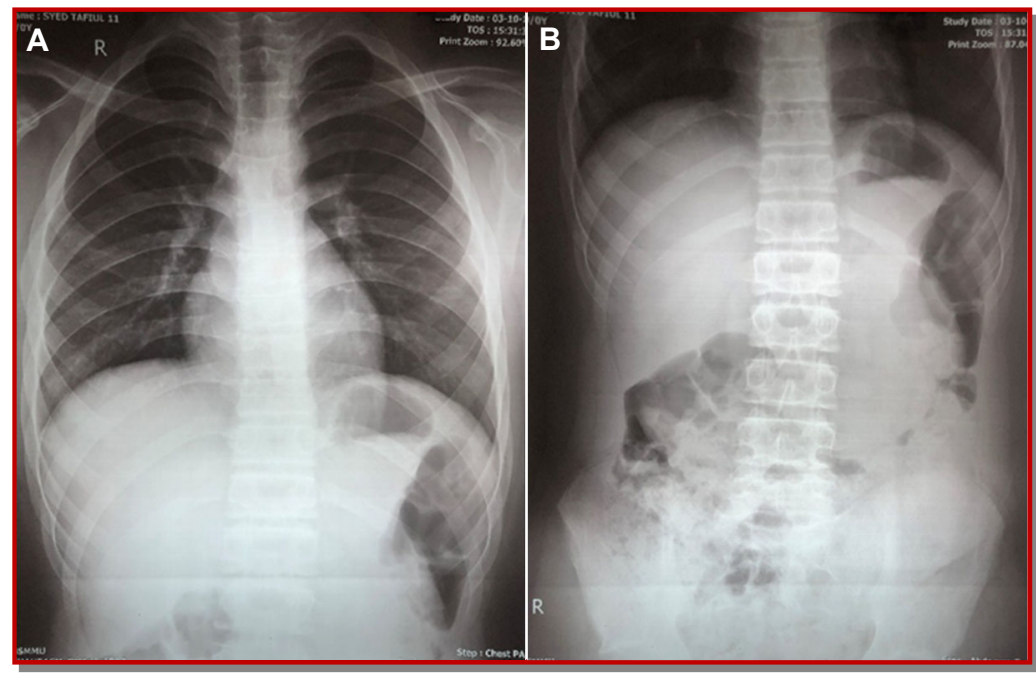

Figure 1: X-ray P/A view of the chest (A) and abdomen (B)

c) unpasteurized cow's milk ingestion; d) lymphatic spread from the adjacent lymph nodes and e) direct spread from an adjacent organ. The most common site of involvement of intestinal tuberculosis is the ileocaecal region.2 There are 3 forms of intestinal tuberculosis: ulcerative, hypertrophic or ulcerohypertrophic or fibrous structuring form. 3 The patient may present with the fever, night sweats, weight loss, altered bowel habit, abdominal pain, and occasional right iliac fossa mass. Diarrhea in the intestinal tuberculosis results from the intestinal mucosal ulceration..$\underline{-}$

This patient presented with chronic diarrhea and significant weight loss which are suggestive of intestinal tuberculosis, but no history of fever, abdominal pain, cow's milk ingestion, no contact history with tuberculosis patient, and no lymphadenopathy go against the intestinal tuberculosis.

The final diagnosis is based on the clinical features, culture and polymerase chain reaction (PCR) for $M$. tuberculosis, tuberculin sensitivity test, radiological investigations (plain and contrast X-ray of the barium meal, follow-through, enema) colonoscopic and histopathological findings. Plain X-ray of the abdomen may show signs of obstruction (presence of multiple air-fluid levels and dilated bowel loops) and/or feature of perforation (air under diaphragm) and calcified abdominal lymph nodes. Contrast studies help to demonstrate the intestinal mucosal pathology. The histopathological hallmarks of tuberculosis are confluent, caseating granulomas having acid-fast bacilli surrounded by lymphoid tissue. In this patient tuberculin sensitivity test was negative, plain X-ray of the abdomen was normal, colonoscopy showed no involvement in the ileocaecal region and histopathology showed no caseating granuloma.

\section{Inflammatory bowel disease}

Dr. Bodhrun Naher: Chronic diarrhea is a common presenting feature of inflammatory bowel disease. Other features are weight loss, abdominal pain and per rectal bleeding. It is a chronic inflammatory disease of the gastrointestinal tract. It occurs as a result of dysregulation of the mucosal immune response against the commensal intestinal microbiota due to multiple factors like genetic, environmental and the microbiome. 5 It has two main subtypes, ulcerative colitis and Crohn's disease. Ulcerative colitis is diffuse, continuous inflammation of the colon extending from the rectum proximally. Crohn's disease can involve any part in the gastrointestinal system from the mouth to the anus but most commonly involves the terminal ileum and colon can present with skip lesions. The presentation of inflammatory bowel disease in children can be variable. 6 Besides the classical features, children may also present with growth failure, anemia, perianal disease, or other extraintestinal manifestations. 7 In case of this patient, there was only features of chronic diarrhea and weight loss.

Laboratory findings in children with inflammatory bowel disease show anemia, thrombocytosis, hypoalbuminemia, and elevated levels of inflammatory markers like ESR and C-reactive protein. 8 Stool needs to be examined for the occult blood, bacterial pathogens (including Clostridium difficile), ova, and parasites and fecal calprotectin. Imaging studies 


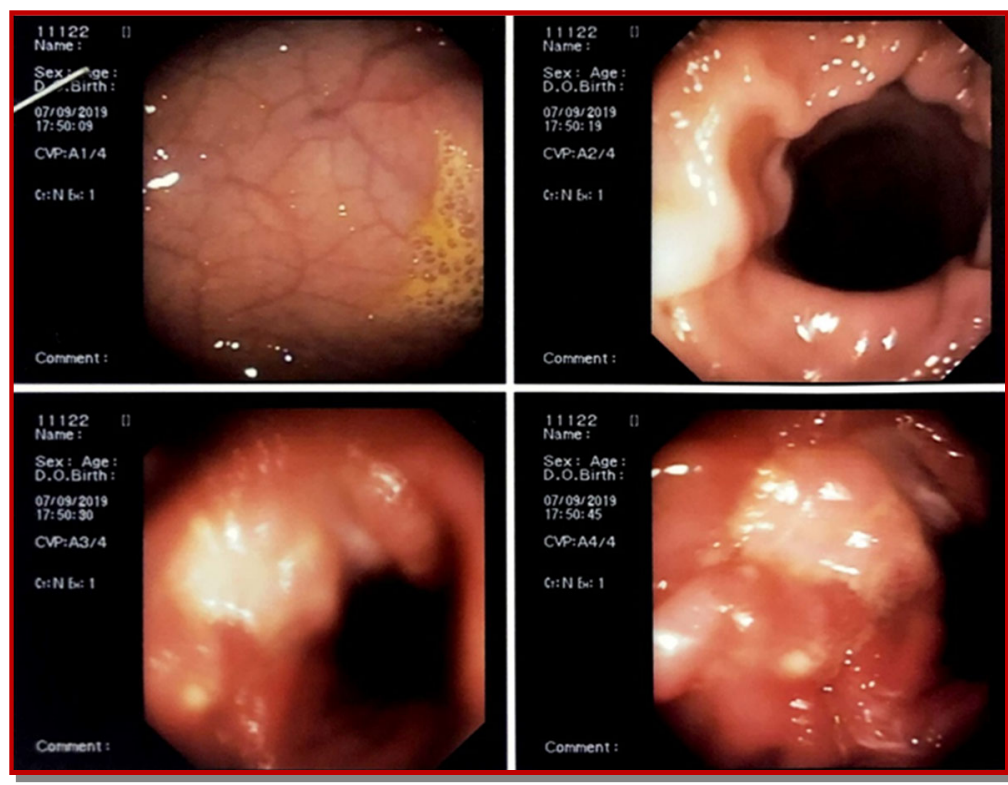

Figure 2: Colonoscopic finding showing rectal mucosal nodularity and ulceration. The mucosa and vascular pattern of the rest of the colon appear to be normal

including plain and contrast X-ray, endoscopy of the upper and lower gastrointestinal tract with histopathology play important roles in establishing the diagnosis. The plain X-ray abdomen may show distended bowel loop, thumb printing sign and loss of haustration. The contrast X-ray shows pathology in the gastrointestinal tract. A colonoscopy reveals aphthous ulcer, linear ulcer, a cobblestone appearance, fistula, stricture and diffuse superficial ulceration of colon. Histological hallmarks of Crohn's disease are intramural and submucosal involvement and presence of non-caseating granuloma. In case of ulcerative colitis, inflammation limited to the mucosa, crypt abscess, cryptitis, and depletion of goblet cells may be present. In this case, none of the findings was present.

\section{Dr. Sayeed's Diagnosis}

Solitary rectal ulcer syndrome

\section{Discussion}

Prof. Rukunuzzaman: The solitary rectal ulcer syndrome is an uncommon, benign and chronic disease of the rectum. It affects predominantly adults and rare in children. 9 Its incidence was at 1 in 100,000 per year. Men and women are equally affected but there is a small predominance in women.10 The condition was first reported by Cruveilhier in 1830, the term solitary rectal ulcer syndrome was first used by Dr. Lloyd-Davis in the 1930s. Thereafter, its clinical and histopathological features were described by Dr. Madigan in 1969..11,12 Solitary rectal ulcer syndrome is sometimes diag-

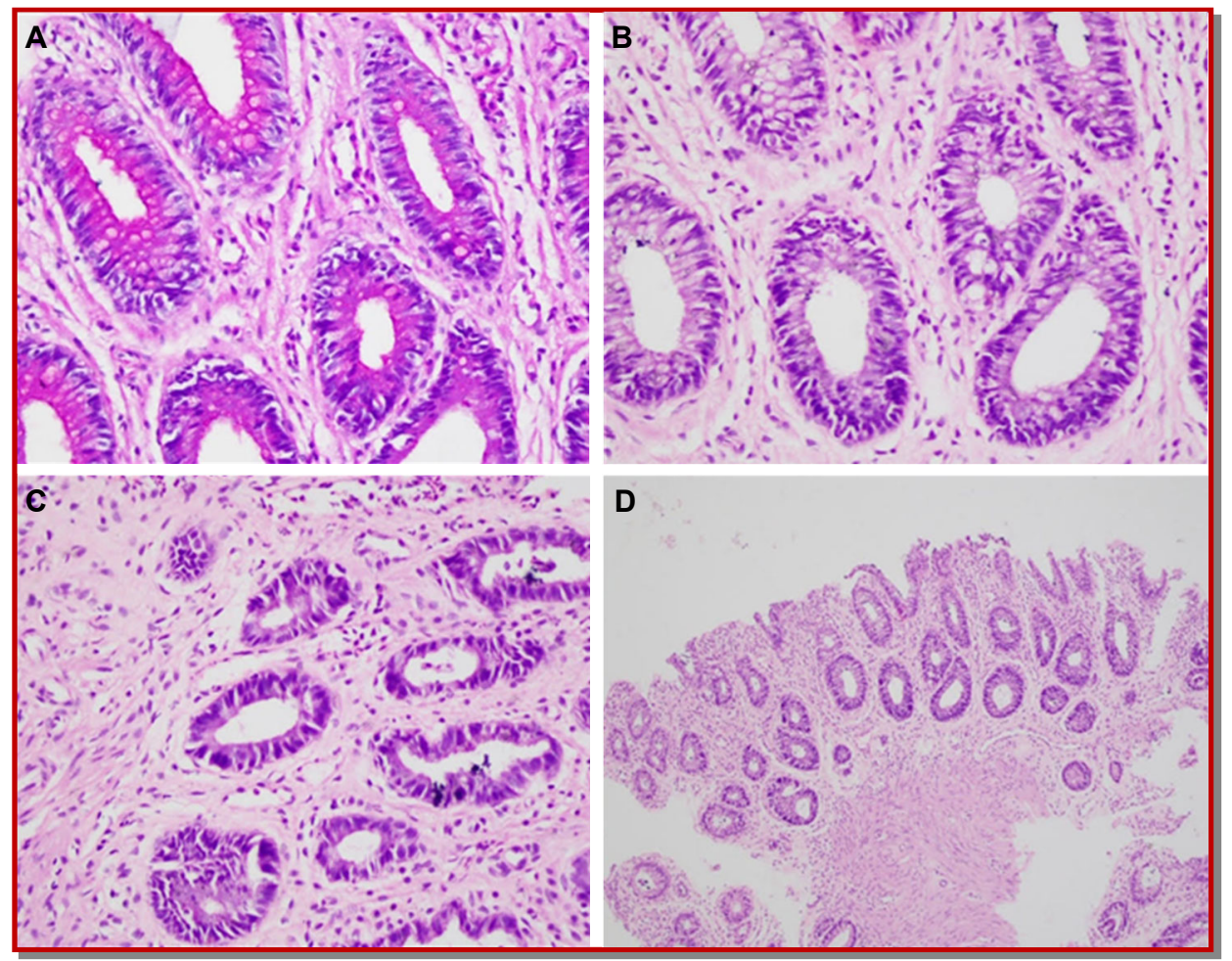

Figure 3: Histopathology showing superficial ulceration and mild infiltration of chronic inflammatory cells in the lamina propria. The crypts hyperplasia, elongation are some diamond shaped crypts are present. The muscularis mucosae are present in between the crypts having thick and thin bands of smooth muscle fibers 
nosed late or misdiagnosed due to its variable presentation. It is a misnomer because ulcers are found in $40 \%$ cases, while $20 \%$ of the cases present with solitary ulcer and rest of the lesions are variable including hyperemic mucosa to the (broadbased) polypoid lesion. $\underline{13}$ The lesion may also involve the sigmoid colon. $\underline{14}$

The pathogenesis of solitary rectal ulcer syndrome is not well-known. But it is believed that multiple factors contribute to developing this condition. Most accepted theories as the causes are related to local ischemia or direct trauma. 15 a) Straining: excessive straining during defecation in a patient who suffers from constipation may cause direct trauma to the mucosa; 16 b) self-induced trauma: self -instrumentation or self-digitation in an attempt to remove impacted stool can cause direct trauma; $\underline{15,17}$ c) paradoxical contraction of puborectalis muscle: uncoordinated contraction in the puborectalis muscle is associated with increased pressure of intra rectum and anal canal causing ischemia and ulceration; $\underline{15,18}$ d) rectal prolapse and intussusception: this can lead to localized vascular trauma resulting in local ulceration. 19

Patients typically present with per rectal bleeding, tenesmus, copious mucous discharge, prolong excessive straining, perianal and abdominal pain, feeling of incomplete defecation, constipation, and rarely rectal prolapse. $20-22$ The amount of blood loss varies from a small amount of fresh blood to severe hemorrhage that may require a blood transfusion.23 Often children may present with apparent diarrhea (because of prolonged visits to the toilet), pain, tenesmus, weight loss, suggest to clinicians that the presence of inflammatory bowel disease. $\underline{24}$ The complaints of diarrhea arose due to frequent passage of mucus. Patients with solitary rectal ulcer syndrome attempt to defecate about 10-11 times per day and about half of them experience toilet visit lasting more than 15 min. .25 It is unusual and a child may present with recurrent per rectal bleeding and severe anemia requiring a blood transfusion. $.6 \mathrm{Up}$ to $26 \%$ of patients can remain asymptomatic and diagnosed incidentally while investigating other diseases. $\underline{13}$

The diagnosis of solitary rectal ulcer syndrome is based on the clinical features, proctosigmoidoscopy findings, and histopathological examination. .27 A thorough and complete history are the most important in the initial diagnosis. The differential diagnosis includes intestinal tuberculosis, inflammatory bowel disease, ischemic colitis and malignancy. Per rectal bleeding may be misinterpreted as a case of anal fissure caused by constipation or as other cause of per rectal bleeding such as a juvenile colonic polyp. 16,28

Colonoscopy and biopsy should be performed from normal and abnormal-looking rectal and colonic mucosa.22 The ulcer is commonly located on the anterior wall of the rectum and the distance of the ulcer varies from 3 to $10 \mathrm{~cm}$ from the anal margin. 11 The diameter of the ulcer ranges from 0.5 to $4 \mathrm{~cm}$ but usually 1-1.5 cm. $\underline{13}$ Appearance of the ulcer may vary from per ulcer that covered by a white, grey or yellowish slough.11,13 The lesion may appear as shallow ulcer and the adjacent mucous membrane may appear nodular, granular or lumpy.29 The polypoid lesion may found in $25 \%$ cases of solitary rectal ulcer syndrome, patchy mucosal erythema may appear in $18 \%$ cases and multiple lesions may found in $30 \%$ cases.22 As a result of the wide range of macroscopic findings of solitary rectal ulcer syndrome, the condition may go unrecognized or misdiagnosed, so it is important to collect biopsy specimen from the lesion site to confirm the diagnosis and to exclude the differentials. 10

Dr. Dey: Histological features of solitary rectal ulcer syndrome are superficial ulcer, mild inflammation, fibromuscular obliteration of lamina propria, muscularis mucosa is hypertrophied having thick and thin bands of smooth muscle with an extension of muscle fibers upwards between the crypts. The crypts are hyperplastic elongated along with some diamond-shaped crypts and crypt glandular abnormalities. $\underline{30}$

Dr. Khan Lamia Nahid: Some imaging investigations can help in the diagnosis of solitary rectal ulcer syndrome including defecating proctography, dynamic magnetic resonance imaging and anorectal functional studies that are manometry and electromyography. 27

Defecography, useful in determining the presence of intussusception or mucosal prolapse, can identify a hidden prolapse, non-relaxing puborectalis muscle, delayed or incomplete rectal emptying. $\underline{31}$ Defecography is usually reserved possibly for preoperative assessment. .22

Barium enema shows thickened rectal folds, rectal stricture, and ulceration, polypoid lesion, the granularity of the mucosa but all of these are nonspecific findings. $\underline{33}$

Anorectal manometry and electromyography give important information about the anorectal inhibitory reflex, defecation dynamics, pressure profile, rectal compliance, and sensory thresholds. $\underline{.2}$

Some studies have shown the usefulness of anorectal ultrasound in assessing the thickness of internal anal sphincter which is increased in solitary rectal ulcer syndrome. $\underline{34}$ The thick internal anal sphincter is highly predictive of high-grade rectal prolapse and rectal intussusception. 35

Routine laboratory tests like hemoglobin, red blood cell counts, white blood cell counts, platelet counts, erythrocyte sedimentation rate, C-reactive protein, liver function tests and coagulation profile are 
usually normal. In a child with a history of recurrent per rectal bleeding may have the feature of microcytic anemia. 27

Prof. Rukunuzzaman: The choice of treatment option depends on the severity of the symptoms and the presence of rectal prolapse. The option for solitary rectal ulcer syndrome includes conservative treatment (ie, diet and bulk laxatives), medical therapy, biofeedback, and surgery. The first step of treatment is the patient education and behavioral modification. $\underline{36}$

In asymptomatic case, the patient may not need any treatment except behavioral modification. Patient should be counseled and reassured that the lesion is benign, high fiber diet should be encouraged, advised to avoid straining, regulation of toilet habit and to discuss any psychosocial factors. $\underline{37}$

In mild to moderate cases with absence of mucosal prolapse, patients may be treated with conservative treatments. Behavioral modification and dietary advice are effective enough. The patient may be treated with bulk laxatives, bowel retraining, and reassurance. $\underline{38}$ The training for prevention of straining and digitation, dietary and behavioral changes should be given.

In the presence of rectal prolapse, high degree of intussusception in rectum and fibrosis, conservative treatment may not be effective and resistance may develop to this therapy. Biofeedback can help in improving symptoms in these patients. Biofeedback includes behavioral changes that are effective in reducing excessive straining during defecation through correction of abnormal pelvic floor behavior and stopping the use of laxatives and suppositories. 16,39 Biofeedback is an useful and appropriate treatment in solitary rectal ulcer syndrome and as a result of increased rectal mucosal blood flow, an appropriate result can be achieved. $\underline{40}$ Its short-term effect is beneficial because in the long -term, it is not effective.22,37 In some patients with long-term therapy may show reduced effect.11

Topical therapy with sucralfate enema, corticosteroid or sulfasalazine improved the symptoms. $\underline{16}$, 22,42 Topical glucocorticoids, salicylates, and botulinum toxins also used in some cases but they seem to be less suitable for the treatment.. $.2,43$

Surgical treatment is suggested in a patient with full-thickness or rectal mucosal prolapse or those who are resistant to conservative therapy and biofeed-back treatments. $.22,44$ Surgical options include rectopexy, perineal proctectomy, excision, diversion as well as Delorme procedure as mucosal resection. $\underline{22,44,45}$

Dr. Sharmin Akter: What is the management plan of this patient?

Dr. Nazmul Hassan: An increase in dietary fibers and regular use of bulk laxatives were advised, biofeed-back therapy was recommended. He was prescribed with sucralfate enema twice daily. He is presently discharged and being followed-up with ongoing therapy.

Dr. Aysha Sabiha: How does sucralfate enema act in solitary rectal ulcer?

Dr. Sayeed: Sucralfate is a sulfated disaccharide complex with aluminum hydroxide. It is a locally acting anti-ulcer agent. By adhering to the mucosa and forming a viscous coagulum, it helps to shield the base of the ulcer, $\underline{46}$ and form a barrier against the irritants.22 Because of its non-systemic, cytoprotective effect, it promotes the healing of ulcers. 47

Dr. Mukesh Khadga: How long the treatment will continue?

Dr. Md. Benzamin: There is no treatment protocol present for the children. However, adult patient is recommended topical sucralfate for at least 6 weeks. Depending on the patient's condition, the duration can be adjusted. $\underline{42}$

Dr. Raihanur Rahman: How to follow-up the patient?

Dr. Luthfun Nahar: Follow-up needs to be done both clinical, macroscopy and microscopically. Clinical assessment needs to be done every weekly, macroscopic assessment by sigmoidoscopy every 2 weekly and repeat biopsy at 6 weeks of treatment. $\underline{42}$

Dr. Ferdous Ara: Does steroid has any role in this case?

Dr. Bodhrun Naher: Corticosteroid enema can also be used. It helps to heal ulcers by reducing the inflammatory response. $\underline{4} \underline{3}$

Dr. Urmi Roy: What are the risk factors for developing such condition?

Dr. Sayeed: Multiple factors may be responsible. Constipation, straining during defecation, selfdigitation to remove impacted stool and incoordination in puborectalis muscle contraction.15-17

Dr. Mahmudul Hasan: What are the complications that may develop in solitary rectal ulcer syndrome?

Dr. Benzamin: Massive hemorrhage may be a serious complication..$\underline{48}$ Others are rectal prolapse and rectal intussusception.

\section{Final Diagnosis}

Solitary rectal ulcer syndrome

\section{Acknowledgement}

We acknowledge Prof. Mohammed Kamal, Department of Pathology, Faculty of Basic Science and Paraclinical Science, Bangabandhu Sheikh Mujib Medical University, Dhaka, Bangladesh for his help. 


\section{Conflict of Interest}

Authors declare no conflict of interest.

\section{References}

1. Donoghue HD, Holton J. Intestinal tuberculosis. Curr Opin Infect Dis. 2009; 22: 490-96.

2. Sharma MP, Bhatia V. Abdominal tuberculosis. Indian J Med Res. 2004; 120: 305-15.

3. Engin G, Balk E. Imaging findings of intestinal tuberculosis. J Comput Assist Tomogr. 2005; 29: 3741.

4. Pulimood AB, Amarapurkar DN, Ghoshal U, Phillip M, Pai CG, Reddy DN, Nagi B, Ramakrishna BS. Differentiation of Crohn's disease from intestinal tuberculosis in India in 2010. World J Gastroenterol. 2011; 17: 433-43.

5. Khor B, Gardet A, Xavier RJ. Genetics and pathogenesis of inflammatory bowel disease. Nature 2011; 474: 307-17.

6. Kugathasan S, Judd RH, Hoffmann RG, Heikenen J, Telega G, Khan F, Weisdorf-Schindele S, San Pablo W Jr, Perrault J, Park R, Yaffe M, Brown C, RiveraBennett MT, Halabi I, Martinez A, Blank E, Werlin SL, Rudolph CD, Binion DG. Epidemiologic and clinical characteristics of children with newly diagnosed inflammatory bowel disease in Wisconsin: A statewide population-based study. J Pediatr. 2003; 143: 525-31.

7. Griffiths AM. Specificities of inflammatory bowel disease in childhood. Best Pract Res Clin Gastroenterol. 2004; 18: 509-23.

8. Mack DR, Langton C, Markowitz J, LeLeiko N, Griffiths A, Bousvaros A, Evans J, Kugathasan S, Otley A, Pfefferkorn M, Rosh J, Mezoff A, Moyer S, Oliva-Hemker M, Rothbaum R, Wyllie R, delRosario JF, Keljo D, Lerer T, Hyams J. Laboratory values for children with newly diagnosed inflammatory bowel disease. Pediatrics 2007; 119: 1113-19.

9. Rutter KR, Riddell RH. The solitary ulcer syndrome of the rectum. Clin Gastroenterol. 1975; 4: 505-30.

10. Martin CJ, Parks TG, Biggart JD. Solitary rectal ulcer syndrome in Northern Ireland. 1971-1980. Br J Surg. 1981; 68: 744-47.

11. Madigan MR, Morson BC. Solitary ulcer of the rectum. Gut 1969; 10: 871-81.

12. Cruveilhier J. Ulcere chronique du rectum. Anatomie Pathologique du Corps Humain. 1829; 2: 4.

13. Tjandra JJ, Fazio VW, Church JM, Lavery IC, Oakley JR, Milsom JW. Clinical conundrum of solitary rectal ulcer. Dis Colon Rectum. 1992; 35: 227-34.

14. Burke AP, Sobin LH. Eroded polypoid hyperplasia of the rectosigmoid. Am J Gastroenterol. 1990; 85:
975-80.

15. Latos W, Kawczyk-Krupka A, Ledwon A, SieronStoltny K, Sieron A. Solitary rectal ulcer syndromeThe role of autofluorescence colonoscopy. Photodiagn Photodyn Ther. 2007; 4: 179-83.

16. Sharara AI, Azar C, Amr SS, Haddad M, Eloubeidi MA. Solitary rectal ulcer syndrome: Endoscopic spectrum and review of the literature. Gastrointest Endosc. 2005; 62: 755-62.

17. Contractor $\mathrm{TQ}$, Contractor $\mathrm{QQ}$. Traumatic solitary rectal ulcer in Saudi Arabia: A distinct entity? J Clin Gastroenterol. 1995; 21: 298-300.

18. Morio O, Meurette G, Desfourneaux V, D'Halluin PN, Bretagne JF, Siproudhis L. Anorectal physiology in solitary ulcer syndrome: A case-matched series. Dis Colon Rectum. 2005; 48: 1917-22.

19. Nagar AB. Isolated colonic ulcers: Diagnosis and management. Curr Gastroenterol Rep. 2007; 9: 42228.

20. Suresh N, Ganesh R, Sathiyasekaran M. Solitary rectal ulcer syndrome: A case series. Indian Pediatr. 2010; 47: 1059-61.

21. Borrelli $\mathrm{O}$, de' Angelis G. Solitary rectal ulcer syndrome: It's time to think about it. J Pediatr Gastroenterol Nutr. 2012; 54: 167-68.

22. Zhu QC, Shen RR, Qin HL, Wang Y. Solitary rectal ulcer syndrome: Clinical features, pathophysiology, diagnosis and treatment strategies. World J Gastroenterol. 2014; 20: 738-44.

23. Bishop PR, Nowicki MJ, Subramony C, Parker PH. Solitary rectal ulcer: A rare cause of gastrointestinal bleeding in an adolescent with hemophilia A. J Clin Gastroenterol. 2001; 33: 72-76.

24. Blackburn C, McDermott M, Bourke B. Clinical presentation of and outcome for solitary rectal ulcer syndrome in children. J Pediatr Gastroenterol Nutr. 2012; 54: 263-65.

25. Sitzler PJ, Kamm MA, Nicholls RJ, McKee RF. Long -term clinical outcome of surgery for solitary rectal ulcer syndrome. Br J Surg. 1998; 85: 1246-50.

26. Tandon RK, Atmakuri SP, Mehra NK, Malaviya AN, Tandon HD, Chopra P. Is solitary rectal ulcer a manifestation of a systemic disease? J Clin Gastroenterol. 1990; 12: 286-90.

27. Keshtgar AS. Solitary rectal ulcer syndrome in children. Eur J Gastroenterol Hepatol. 2008; 20: 89-92.

28. Daya D, O'Connell G, DeNardi F. Rectal endometriosis mimicking solitary rectal ulcer syndrome. Modern pathology: An official journal of the United States and Canadian Academy of Pathology, Inc. 1995; 8: 599-602.

29. Figueroa-Colon R, Younoszai MK, Mitros FA. Solitary ulcer syndrome of the rectum in children. J Pediatr Gastroenterol Nutr. 1989; 8: 408-12.

30. Chiang JM, Changchien CR, Chen JR. Solitary rectal 
ulcer syndrome: An endoscopic and histological presentation and literature review. Int J Colorectal Dis. 2006 ; 21 : 348-56.

31. Goei R, Baeten C, Arends JW. Solitary rectal ulcer syndrome: Findings at barium enema study and defecography. Radiology 1988; 168: 303-06.

32. Halligan S, Nicholls RJ, Bartram CI. Proctographic changes after rectopexy for solitary rectal ulcer syndrome and preoperative predictive factors for a successful outcome. Br J Surg. 1995; 82: 314-17.

33. Millward SF, Bayjoo P, Dixon MF, Williams NS Simpkins KC. The barium enema appearances in solitary rectal ulcer syndrome. Clin Radiol. 1985; 36 : 185-89.

34. Gopal DV, Young C, Katon RM. Solitary rectal ulcer syndrome presenting with rectal prolapse, severe mucorrhea and eroded polypoid hyperplasia: Case report and review of the literature. Can J Gastroenterol. 2001; 15: 479-83.

35. Marshall M, Halligan S, Fotheringham T, Bartram C, Nicholls RJ. Predictive value of internal anal sphincter thickness for diagnosis of rectal intussusception in patients with solitary rectal ulcer syndrome. Br J Surg. 2002; 89: 1281-85.

36. Ignjatovic A, Saunders BP, Harbin L, Clark S Solitary rectal ulcer syndrome in the sigmoid colon. Colorectal Dis. 2010; 12: 1163-64.

37. Malouf AJ, Vaizey CJ, Kamm MA. Results of behavioral treatment (biofeedback) for solitary rectal ulcer syndrome. Dis Colon Rectum. 2001; 44: 72-76.

38. Forootan M, Darvishi M. Solitary rectal ulcer syndrome: A systematic review. Medicine 2018; 97: e0565.

39. Vaizey CJ, Roy AJ, Kamm MA. Prospective evaluation of the treatment of solitary rectal ulcer syn- drome with biofeedback. Gut 1997; 41: 817-20.

40. Jarrett ME, Emmanuel AV, Vaizey CJ, Kamm MA. Behavioural therapy (biofeedback) for solitary rectal ulcer syndrome improves symptoms and mucosal blood flow. Gut 2004; 53: 368-70.

41. Binnie NR, Papachrysostomou M, Clare N, Smith AN. Solitary rectal ulcer: The place of biofeedback and surgery in the treatment of the syndrome. World J Surg. 1992; 16: 836-40.

42. Zargar SA, Khuroo MS, Mahajan R. Sucralfate retention enemas in solitary rectal ulcer. Dis Colon Rectum. 1991; 34: 455-57.

43. Bulut T, Canbay E, Yamaner S, Gulluoglu M, Bugra D. Solitary rectal ulcer syndrome: Exploring possible management options. Int Surg. 2011; 96: 45-50.

44. Torres C, Khaikin M, Bracho J, Luo CH, Weiss EG, Sands DR, Cera S, Nogueras JJ, Wexner SD. Solitary rectal ulcer syndrome: Clinical findings, surgical treatment, and outcomes. Int J Colorectal Dis. 2007; 22: 1389-93.

45. Kargar S, Salmanroughani H, Binesh F, Taghipoor S, Kargar S. Laparoscopic rectopexy in solitary rectal ulcer. Acta Med Iran. 2011; 49: 810-13.

46. Nagashima R. Development and characteristics of sucralfate. J Clin Gastroenterol. 1981; 3: 103-10.

47. Rey JF, Legras B, Verdier A, Vicari F, Gorget C. Comparative study of sucralfate versus cimetidine in the treatment of acute gastroduodenal ulcer: Randomized trial with 667 patients. Am J Med. 1989; 86: 116-21.

48. Misumi A, Sera Y, Matsuda M, Inamori Y, Kawano H, Takano S, Murakami A, Akagi M. Solitary ulcer of the rectum: Report of a case and review of the literature. Gastroenterol Jpn. 1981; 16: 286-94. 